Universidade Técnica de Lisboa

Faculdade de Motricidade Humana

\title{
Manual asymmetries in bimanual isochronous tapping tasks in children
}

\section{Dissertação elaborada com vista à obtenção do Grau de Mestre em Desenvolvimento da Criança na Variante de \\ Desenvolvimento Motor}

\section{Orientadora}

Doutora Ana Maria Fité Alves Diniz

\author{
Júri \\ Presidente: Doutor João Manuel Pardal Barreiros \\ Vogais: Doutora Maria Olga Fernandes Vasconcelos \\ Doutora Ana Maria Fité Alves Diniz
}

INÊS FARIA DA SILVA 
Universidade Técnica de Lisboa

Faculdade de Motricidade Humana

\title{
Manual asymmetries in bimanual isochronous tapping tasks in children
}

\section{Dissertação elaborada com vista à obtenção do Grau de Mestre em Desenvolvimento da Criança na Variante de \\ Desenvolvimento Motor}

\author{
Orientadora \\ Doutora Ana Maria Fité Alves Diniz \\ Júri \\ Presidente: Doutor João Manuel Pardal Barreiros \\ Vogais: Doutora Maria Olga Fernandes Vasconcelos \\ Doutora Ana Maria Fité Alves Diniz
}

INÊS FARIA DA SILVA 


\section{Agradecimentos}

À Professora Doutora Ana Diniz, por toda a ajuda e dedicação nesta primeira aventura como orientadora. Espero ter deixado vontade de repetir...

Ao Professor Doutor João Barreiros, pela motivação, pelo subtil poder de persuasão e pelo constante borbulhar de ideias.

Aos participantes, adultos e crianças, que se disponibilizaram simpaticamente.

À família e amigos, pela preocupação e apoio incondicionais.

MUITO OBRIGADO! 


\begin{abstract}
The reasons why some people use preferably one hand to perform everyday tasks instead of the other are still the object of study of many investigators. Even if ambidexterity would seem an advantage, the fact is, even small babies show preferences for one side over the other on their most basic movements. These lateral asymmetries are always present but suffer fluctuations throughout life and even from one activity to another, performed minutes later.

A very common and effective way of studying manual asymmetries is through tapping tasks, following and adapting the models of authors like Stevens (1886) and Wing and Kristofferson (1973). These authors showed the scientific community that the synchronization-continuation experiments were valid and could be used to investigate the process of timekeeping and a variety of different aspects related to motor control.

Our work was based on these previous investigations and has the purpose of analyzing the ability of keeping a rhythm, in children on a bimanual tapping task, as well as the manual asymmetries displayed while doing so. The children's performance was compared to that of adult musicians, who are expected to have a better than average performance on this type of tasks.
\end{abstract}

Key words: manual asymmetries, handedness, tapping, time perception, children, musicians. 


\section{RESUMO}

As razões que levam alguém a usar preferencialmente uma das mãos na execução de tarefas diárias em detrimento da outra, são o objecto de estudo de muitos investigadores. Apesar da ambidestria parecer uma vantagem, facto é que mesmo os bebés revelam preferência por um dos lados sobre o outro nos seus movimentos mais básicos. Estas assimetrias laterais estão sempre presentes mas sofrem alterações ao longo da vida, e mesmo de uma actividade para a outra, realizada minutos depois.

Uma forma de estudar assimetrias manuais são as tarefas de tapping, seguindo os modelos de autores como Stevens (1886) e Wing e Kristofferson (1973). Estes mostraram à comunidade científica que os estudos de sincronização-continuação eram válidos e poderiam ser utilizados na investigação de processos de controlo do tempo e de diferentes aspectos relacionados com o controlo motor.

O nosso trabalho teve por base as investigações referidas e tem como objectivo analisar a capacidade de um grupo de crianças em manter um ritmo durante uma tarefa de tapping bimanual, assim como as assimetrias manuais que revelam durante a mesma. $\mathrm{O}$ desempenho das crianças foi comparado com o de músicos adultos, que se prevê que tenham um desempenho superior à média neste tipo de tarefas.

Palavras-Chave: assimetria manual, lateralidade, tapping, percepção de tempo, crianças, músicos. 
INDEX

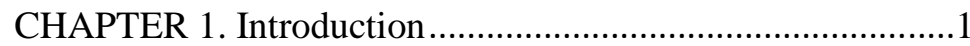

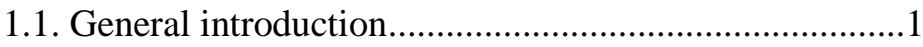

1.2. Development of handedness and manual asymmetry ...1

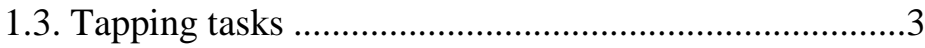

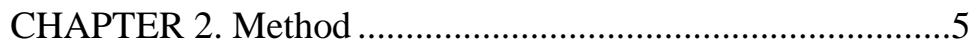

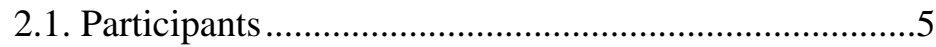

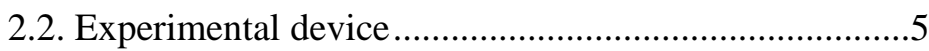

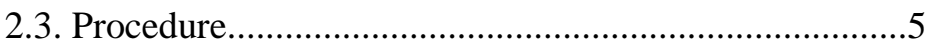

CHAPTER 3. Results and Discussion......................................

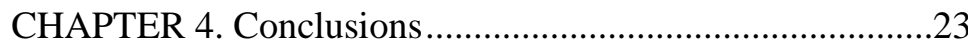

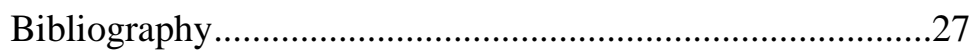

APPENDIX 1: Child C1 Graphs

APPENDIX 2: Child C12 Graphs

APPENDIX 3: Adult A1 Graphs 


\section{INDEX OF TABLES AND FIGURES}

Table 1 ..................................................................................... 7

Table 2 ................................................................................. 8

Table 3 .................................................................................. 8

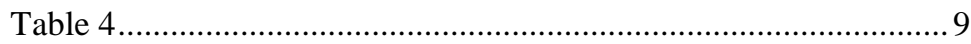

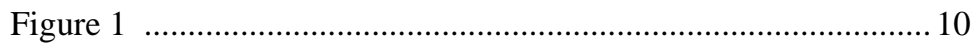

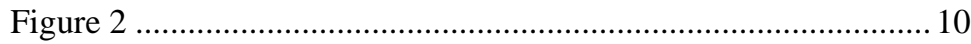

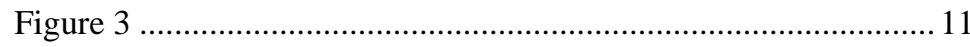

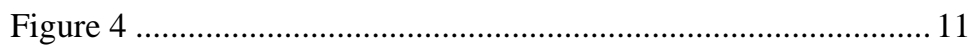

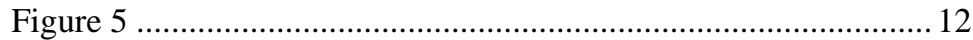

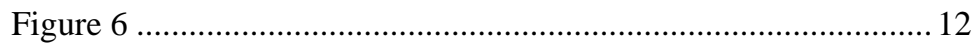

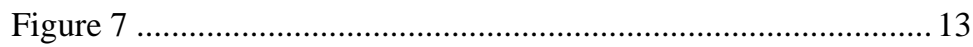

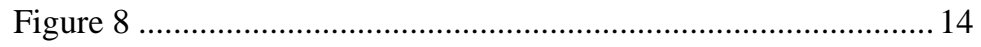

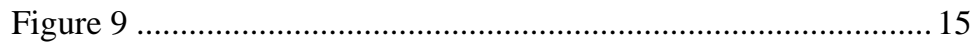

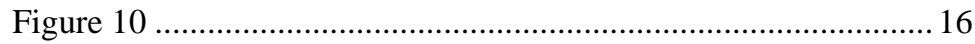

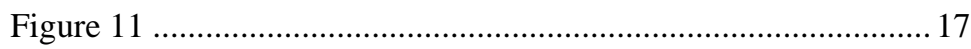

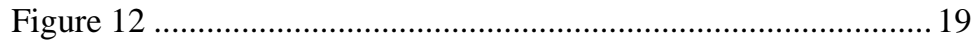

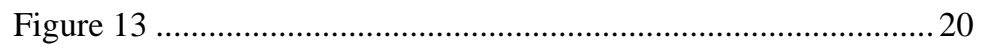

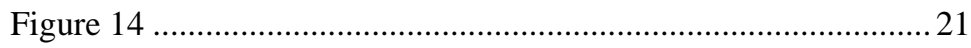

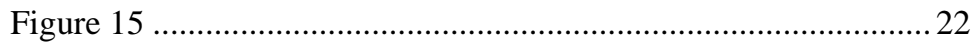

